Meta

Journal des traducteurs

Translators' Journal

\title{
Management et marketing
}

\section{La rédaction}

Volume 14, numéro 2, juin 1969

URI : https://id.erudit.org/iderudit/003993ar

DOI : https://doi.org/10.7202/003993ar

Aller au sommaire du numéro

Éditeur(s)

Les Presses de l'Université de Montréal

ISSN

0026-0452 (imprimé)

1492-1421 (numérique)

Découvrir la revue

Citer cet article

La rédaction (1969). Management et marketing. Meta, 14(2), 102-103.

https://doi.org/10.7202/003993ar

Ce document est protégé par la loi sur le droit d'auteur. L’utilisation des services d'Érudit (y compris la reproduction) est assujettie à sa politique d'utilisation que vous pouvez consulter en ligne.

https://apropos.erudit.org/fr/usagers/politique-dutilisation/
Cet article est diffusé et préservé par Érudit.

Érudit est un consortium interuniversitaire sans but lucratif composé de l’Université de Montréal, l'Université Laval et l'Université du Québec à Montréal. Il a pour mission la promotion et la valorisation de la recherche. https://www.erudit.org/fr/ 


\section{MANAGEMENT ET MARKETING}

Il est des mots qui tracasseront toujours les traducteurs. L'intégration de certains termes anglais dans la langue française se fait plus ou moins rapidement et avec plus ou moins de bonheur. L'intégration est parfois douloureuse parce qu'elle donne surtout mauvaise conscience.

Management, marketing, planning, control, pour ne citer que ceux-là, continuent à se balancer sur la corde raide de la terminologie française. 
Dans le numéro de décembre 1968 de l'Usine nouvelle, voici ce qu'on trouve sous le titre «Quelques termes essentiels du management moderne et leur signification $\gg$ :

Management: de plus en plus utilisé, ce terme issu du vieux mot italien «maneggiare » regroupe les notions d'organisation, d'administration et de gestion des entreprises.

Ensuite, au bas d'une photographie:

L'ancien immeuble de l'O.T.A.N. à Paris (Porte Dauphine) deviendra la première faculté officielle de l'enseignement du management en France.

L'article en question laisse penser que l'invasion des mots anglais, dont personne ne doute, ne fait que commenccr. En effet, on lit plus loin: "Les H.E.C. et l'E.S.S.E.C. envisagent de faire suivre à certains de leurs diplômés un $3^{e}$ cycle d'études aux États-Unis, pour enseigner ensuite dans leur école d'origine. » Il est probable que ces diplômés rapporteront de leur séjour outre-Atiantique un bagage d'idées nouvelles mais aussi de termes américains, et qu'ils oublieront tout bonnement qu'il existe déjà en français des mots qui leur permettraient de traduire ces idées. On serait tenté de dire comme $M$. Jean Darbelnet dans son ouvrage Regards sur le français actuel que c'est par ignorance qu'on va chercher ailleurs ce qui existe déjà dans sa propre langue.

À propos de marketing, ce même numéro de l'Usine nouvelle cite les définitions suivantes:

Marketing is the performance of business activities that direct the flow of goods and services from producer to consumer or user (American Marketing Association).

Recherches stratégiques commerciales les plus efficaces et conłrôle des opérations lancées en exécution de la stratégie choisie (Comité d'étude des termes techniques - 1963).

Le marketing, c'est l'ensemble de toutes les activités commerciales qui, en partant de la connaissance des besoins et du désir de consommation, tend à diriger les produits actuels et les produits nouveaux vers leurs marchés (Responsables des Centres nationaux de productivité de l'Organisation de coopération et de développement économiques - o.C.D.E.).

Notons en passant que le Comité d'étude des termes techniques traduit marketing au sens large par commercialisation, et au sens restreint par techniques commerciales ou stratégie commerciale.

Daniel Rosseel 